\title{
Journey to a Different Place: Reflections on Taylor Cox, Jr.'s Career and Research as a Catalyst for Diversity Education and Training
}

\author{
STACY D. BLAKE-BEARD \\ Simmons College \\ JOYCELYN A. FINLEY-HERVEY \\ Florida A\&M University \\ CELIA VIRGINIA HARQUAIL \\ AuthenticOrganizations.com
}

\section{INTRODUCTION}

In the preface to his book, Creating the Multicultural Organization (2001), Taylor Cox, Jr., invites readers to "take a journey to a different place on diversity issues." Cox's career has entailed just that-taking readers of his research to new and different places. He has not only charted new territory, but also has enriched diversity education and training by showcasing the theoretical sophistication necessary for understanding, studying, and teaching about organizational diversity.

Cox, an African-American scholar who came of age during segregation and the Civil Rights Movement, grew to become an architect of diversity management. His research, teaching, consulting, and professional advocacy helped to establish a foundation for educators, practitioners, and researchers seeking to understand and manage diversity in organizations. Cox took a personal vision of what diversity could bring to organizations, designed a comprehensive plan for conducting ground-breaking diversity research, and then pursued this plan on several fronts, as a researcher, trainer, and agent of social change. He laid the structural foundation for the cultural diversity landscape by conducting empirical research on multiple dimensions of diversity, including race, gender, national origin, work function, and organization level. His signature contributions to education and training are threefold: (1) exposing dimen- sions of cultural difference while unveiling their interconnectedness and commonalities via theoretical models and experiential exercises; (2) providing educators, diversity consultants, and researchers with common language to talk about the intersection of cultural and physiological characteristics; and (3) highlighting that cultural diversity and organizational culture-together-must be understood and influenced to create effective organizations.

Given the prevalence of diversity research today, it might be easy to overlook the sheer courage that it took for Cox to embark on his ambitious diversity education, training, and research agenda. He reached across a wide range of disciplines to construct a theoretical framework of diversity and tackled on issue that was not considered a legitimate field of academic study. From our perspectives, as colleagues and former doctoral students who had the honor of conducting research with Cox, the risks that he took to advance the study of organizational diversity were significant. In pioneering the important issue, Cox advanced education and training by developing early conceptual models for understanding diversity and multiculturalism (e.g., Cox, 1993); by creating teaching and training tools to help individuals discuss and learn about diversity (e.g., Cox \& Beale, 1997); and by establishing the business case for 
valuing diversity in the workplace (e.g., Cox \& Blake, 1991).

In this essay we share what we learned about Taylor Cox's journey, about his work and about his contributions. We draw on an interview conducted with Cox in September 2007 regarding his life experiences, his thoughts on the complexities of diversity, and his view of the opportunities and challenges that diversity educators, trainers, managers, and researchers continue to face. We also invited several of Cox's coauthors, including both peers and graduate student protégés, to share their perspectives on his contributions to diversity education, training, and research. In addition, we incorporate our own experiences with Cox as well as our professional knowledge of diversity research, teaching, and consulting, to reflect on his contributions to diversity education and training in organizations. In the following sections, we discuss several elements of Cox's journey to a different place: the section entitled Personal Leadership examines the personal and professional drivers that sparked his interest in diversity research, education and training; Research highlights his most significant research publications and discusses how Cox contributed as an academic; Advancing Education and Training by Bridging Research and Practice discusses how Cox integrated his research and consulting to contribute to how we approach diversity education and training; Social Action analyzes his role as a catalyst for change in the academy; and Future Opportunities for Diversity Education, Training and Research shares Cox's insights about emerging trends related to diversity education and training. We begin with Personal Leadership and Research because those factors serve as the foundation for Cox's work as a diversity educator, trainer, and social activist.

\section{Personal Leadership}

\section{Impact of Early Childhood Experiences-Forged in the Crucible of Segregation}

An examination of Cox's personal journey shows the influence of his early childhood on his professional career and research agenda. Cox was born and spent his first years in Clarksburg, West Virginia, during the Jim Crow era. He attended a segregated school and lived in a town where AfricanAmericans could not sit at the front of the theater or be served at the lunch counters. Cox learned invaluable lessons from his father, who was a pioneer in his own right, as one of the early AfricanAmerican MBAs in the United States, earning his degree from Indiana University in 1954. Although
Taylor Cox, Sr., was one of the top students in his class, after graduating, he received no invitations to interview for managerial positions. He returned to Clarksburg where, with two degrees, the only position he could find was parking cars at a garage. Very early on, Cox learned about the importance of social identity factors, particularly race. And he dealt with the real costs of racism-the impact of prejudice on his father's professional career adversely affected his family's financial opportunities.

Cox would have his own encounters with racism. As a teenager, he moved with his family to a Detroit community that was $98 \%$ White. As a resident in this community, Cox was set to attend a predominantly White high school in his neighborhood. However, attending this school was not something to which he looked forward-African-American youth in this area were subject to harassment and even beatings from gangs of White youth. In an effort to avoid his neighborhood school, Cox applied to and was accepted at Cass Technical, a high school in the center of Detroit with a reputation for academic excellence. This decision not only allowed Cox to avoid the emotional and social challenges he would have faced as one of few African-American students in the neighborhood school, but also offered him an academically superior education that prepared him for high academic achievement in college and beyond. These early experiences helped to shape Cox's beliefs about the importance of social identity factors and sparked two questions: (1) "What does it mean to be an African-American in this society?"; and (2) "How important are identity factors such as race in people's life experiences?"

\section{Impact of Career History-Professional Path to Diversity Education, Training, and Research}

Cox majored in business administration, intending to pursue a corporate career. After earning his BA and MBA from Wayne State University, he started on a traditional management path with AT\&T. However, he didn't feel that a Fortune-500 corporate environment was his niche, so, he returned to academics for a $\mathrm{PhD}$ in business administration at the University of Arizona. The road to his PhD was not an easy one. Cox's funding was so limited that, during the last 2 years of his doctoral program, he taught five to six courses a semester at Pima Community College so that he could provide for his family.

Cox took a position as an assistant professor at the University of North Carolina Charlotte (UNCC), where his early research publications focused on 
manufacturing strategy. However, it was here that Cox became interested in race as a variable of study. He reflected:

I wrote a piece in 1983 on education and race that appeared in a little-known journal called the Negro Education Review. In doing that piece, I got immersed in the data, writing on the intersection of race and education from the standpoint of how we did ... well actually, it was about the relationship between education and economic success with race as a moderator of that relationship. That just really piqued my interest. I wrote it really as an essay to African-American students, especially young people who needed a sense of the importance of formal education.

Notice that the relationship Cox explored is the very issue his father faced-despite his father's graduate education, he could not initially obtain suitable employment due to the color of his skin. This article represented an important turning point. Cox began to see management research as a tool to investigate diversity issues. During this time, he also started a consulting firm, Taylor Cox and Associates, to work directly with organizations on their specific diversity education and training opportunities and challenges.

Cox was not at UNCC for long before he was contacted by two Historically Black Colleges and Universities (HBCUs) who offered him administrative leadership positions. He accepted an offer from Johnson C. Smith University as chair of their management program. A year later, Cox moved to Winston-Salem State University as chair of the Division of Business and Economics. Clearly, Cox's management skills were attractive to universities. However, his research skills were also attractive, and after 2 more years as an administrator, the dean of the business school at Duke convinced Cox to join the faculty at The Fuqua School of Business. The Visiting Assistant Research Professor position at Duke allowed Cox the opportunity to shift from an administrative route and to refocus on a teaching and research path. This was a pivotal decision for Cox. As he explained:

Staying at Winston-Salem would have locked me in on an administrative track, which was okay, and I was enjoying it, but by coming to Duke and Michigan-it put me back on the researcher/professor track of teaching and working with students. So that was kind of a critical juncture, and I made the right choice.
In 1988, Cox returned to the Midwest as an assistant professor at the University of Michigan, Ann Arbor. There, he rose through the ranks to become the first African-American professor ever to earn tenure in the University of Michigan School of Business. Cox would spend 13 years in total at the University of Michigan conducting his research, teaching BS, MBA, and executive students, developing $\mathrm{PhD}$ candidates, consulting, and holding professional leadership roles within the university and the academy. At the same time that he was pursuing tenure at the University of Michigan, Cox was also working evenings and weekends as a pastor in a Christion ministry. In 2000, Cox decided to devote himself full time to his Christion ministry, and he retired from the University of Michigan.

Cox's career spanned many roles, including business management, university administration, scholarly research and teaching, organizational consulting, and Christian ministry. In each role, Cox was driven by a desire to teach, mentor, and coach others, including academics, practitioners, and community members, about respecting and valuing people who were different from them. Cox's rare combination of roles begs the question: "What kind of person combines all of these demanding professional roles into one career path?"

\section{Reseorch}

\section{A Comprehensive Approach to Organizational Diversity}

By the end of his academic career, Cox had achieved what many would define as the ultimate scholarly goal: tenure at a top business school. At the University of Michigan, Cox could teach students and executives, interact with highly accomplished colleagues, and pursue an independent research program. It would appear from his vita that Cox deployed conventional tactics to achieve this goal. He identified a gap in our understanding of management and organizations; he developed a comprehensive research agenda to address this gap; and, he pursued this agenda through rigorous empirical and theoretical research projects. Yet along with these conventional tactics, Cox also deployed less common tactics that not only helped him achieve tenure but also extended the impact of his research on diversity education and training. Specifically, Cox integrated theory development and empirical research on diversity with practice as a diversity consultant. Simultaneously, he incorporated insights from his consulting practice into his research questions and findings. And, he 
established productive collaborative relationships with a wide range of coauthors. These relationships, and the research that they generated, helped Cox reach and influence scholars and their efforts on diversity education and training across the academy.

He identified a gap in our understanding
of management and organizations; he
developed a comprehensive research
agenda to address this gap; and, he
pursued this agenda through rigorous
empirical and theoretical research
projects.

\section{A Compelling Gap in Our Understanding of Organizations}

The process of researching and writing his 1983 article about how race affected the relationship between education and economic success opened Cox's eyes to the paucity of research on race and cultural diversity in organizations. As he explained,

I became increasingly aware of the need for more and better research on social identity factors, and especially to have this research appear in major journals of the Academy and to get more people involved in the Academy looking at work in this area. I began to see this as a mission in a sense. I saw a need for [this research] and I wanted to respond to that need. And I frankly saw it as an area of work that was very promising and that was underdeveloped. I thought, "Gee, if I could make a contribution here that would be of some value to the field."

We must remind ourselves that in the early 1980s when Cox was starting his scholarship, research on race, gender, social identity, and diversity was not particularly valued or welcomed. When asked whether he perceived any risks in taking on the topic of cultural diversity, he answered without hesitation:

There's no question that this was prominent in my thinking .... There were two primary risk factors that we thought of. One [risk] was: Here's a field that's not really accepted in the Academy, not really viewed as "mainstream science. We hadn't seen much work in this field published in AMJ and ASQ and AMR ...
So there was a general career risk for anybody that wanted to specialize in this field of study. And I know for sure that many scholars were concerned about that.

The other piece was, as racial minority scholars, there was the additional issue of "Will people just see this as self-serving work?" You're studying yourself, and you are interested in this because you are a racial minority, and that will trivialize it as just a piece of self-serving work ... All of these things could cause people to discount your work or question your motives.

For Cox, furthering diversity education was important enough that he was willing to take the risks of having his research discounted or having his motives questioned.

\section{Pursuing an Ambitious Research Agenda}

Cox was determined to address these risks in the best scholarly fashion, by developing a broad, multilevel research agenda that built a comprehensive foundation for understanding diversity and its impact in organizations. Two features of his research agenda are critical for explaining his lasting impact on diversity education: One is the sheer breadth of his efforts. Cox thought expansively about diversity-not just about one study, one level of analysis, or one dimension of diversity. He was interested not only in how diversity influenced a particular organizational outcome, but also in diversity's influence across a range of different organizational processes and outcomes, and across the organization itself. Moreover, Cox published his research in a variety of outlets, including Negro Educational Review, Sex Roles, Small Group Research, Journal of Applied Psychology, Journal of Vocational Behavior, and the Academy of Management Journal. While it was important to target the most prestigious journals, it was also critical to reach a variety of scholars across management disciplines and academic fields. The variety of outlets in which Cox published enabled his research to influence management scholars in many different areas, as well as diversity scholars outside of the Academy of Management.

The second feature is Cox's fundamental belief about the potential relationship between diversity and organizations. Cox wanted to understand diversity in organizations and he wanted to reduce racism, sexism, and discrimination within organizations. Just as important, and critical for explaining his impact, is that Cox studied diversity with a 
specific business goal in mind. His guiding premise was that "diversity as a characteristic of human social systems can, under the right circumstances, enhance organizational effectiveness." While this business-oriented approach is taken for granted now, 25 years ago this approach was innovative. Cox insisted that an organization's overall effectiveness was directly linked to its approach to multiculturalism. The promise of this link made diversity initiatives and training palatable, and even desirable, to organizations.

To demonstrate this link, Cox began with a series of articles exploring the impact of race, gender, age, and other social and cultural differences on human behavior at work. His early research with Stella Nkomo focused on race and gender as dimensions of diversity. With large data sets, they empirically examined the impact of race on performance appraisals (Cox \& Nkomo, 1986); and on upward mobility (Nkomo \& Cox, 1989, 1990). They compared the experiences of managers grouped by race (1986, 1990); Black managers grouped by gender (1989); and managers grouped by gender versus managers grouped by race (1991). This series of studies by Cox and Nkomo represents one of the first attempts to understand the intersectionality of race and gender as categories of individual difference that influenced a manager's career success. Also with this series of articles, Cox and Nkomo set a precedent for purposefully grounding research on diversity in organizations in the findings and frameworks of several different disciplines, including sociology, psychology, and economics. This approach allowed them to go beyond simply documenting race and gender discrimination in organizations to offer a multidisciplinary theoretical explanation for these outcomes. Educators, trainers, and managers benefit from their practice of grounding their research in an array of academic disciplines; Cox and Nkomo's work provides a model of how important it is to address diversity issues from a variety of frameworks, ranging from psychologically based tools to sociologically grounded structural analyses of organizational culture, systems, and processes.

In a second stream of research, Cox and his colleagues Poppy McLeod and Sharon Lobel examined group-level dimensions of diversity (Cox, Lobel, \& McLeod, 1991; McLeod, Lobel, \& Cox, 1996). Comparing groups from different cultural traditions, their lab studies demonstrated that ethnically diverse groups composed of Asians, Blacks, Hispanics, and Anglos acted more cooperatively than all-Anglo groups (1991). In another set of lab studies, they found that ethnically diverse small groups were more creative than ethnically homogenous ones (1996).

Cox also established a stream of research at the organizational level of analysis. Three articles published in 1991 and directed toward practitioners offered a theoretical typology, a set of objectives, strategies, and tools, and a compelling business argument for organizational diversity. In "Models of Acculturation for Intraorganizational Diversity" (1991), Cox and Joycelyn Finley-Nickelson explained how an organization's monolithic, pluralistic, or multicultural organizational culture influenced how it could respond to diversity initiatives. In "The Multicultural Organization" (Cox, 1991), Cox expanded this framework, analyzed an array of organizational strategies, and recommended several tools for moving toward an organization where members from all identity groups were equally engaged and valued. And, with "Managing Cultural Diversity: Implications for Organizational Competitiveness" (1991), Cox and Stacy Blake provided one of the first comprehensive arguments for a business case for diversity. At a time when it was imperative for diversity scholars to interest business school academics and practitioners in moving toward diversity, and even today, this article is widely cited.

\section{Achieving Critical Mass by Integrating Research Streams}

With each stream of research, Cox and his colleagues were providing theories and empirical data that other diversity researchers could cite to support their findings and that diversity educators could use to undergird their teaching efforts. But it wasn't until 1993, with the publication of his book, Cultural Diversity in Organizations: Theory, Research, \& Practice, that Cox's research achieved critical mass. In this ground-breaking work, Cox integrated his different streams of research to create a comprehensive conceptual model of organizational multiculturalism. He used multiple levels of analysis, multiple dimensions of diversity, and multiple categories of difference. He grounded his research in theory and empirical findings drawn from several scholarly disciplines. And, he illustrated his concepts with examples drawn from over a decade of diversity consulting, education, and training. Cultural Diversity in Organizations was one of the very first publications to offer theory that was complex, comprehensive, and innovative in a timely and easily accessible format. Thus, it appealed to educators and practicing managers alike. And, it was one of the first texts on diversity in organizations to be adopted by management 
professors, who used the book as a resource for teaching everything from interpersonal dynamics to strategic human resource management to managing diversity. Because of the book's scope, reach and overall impact, Cultural Diversity in Organizations received the 1994 George R. Terry Book Award for outstanding contribution to advancing management knowledge from the Academy of Management. Thus, through a decade of steadfast focus, Cox helped to change the perception of diversity education, training, and research.

With Cultural Diversity in Organizations, Cox offered educators, trainers, managers and researchers a set of constructs that helped to clarify some of the frustrating complexities of diversity. For example, Cox used his book to introduce and explain his construct of racioethnicity, a term he coined so that those interested in the study and teaching of diversity could have a common language to talk in a new way about the intersection of race, ethnicity, and culture. By defining racioethnicity as racial and/or ethnic distinctiveness (Cox, 1993: 6), this construct helped us embrace the intersectionality of biologically and culturally based differences. The construct simultaneously allows us to acknowledge the socially constructed cultural freight of the concept of biological race while recognizing the ways that we use physical characteristics to create human social categories. This single term, and all the understanding of diversity that it carries, offers an invaluable contribution to diversity education, training, and research.

\section{Advancing Education and Training by Bridging Research and Practice}

Many if not most scholars make their impact on a field through their research and academic writing alone. But Cox, as described by former U.S. Secretary of the Treasury Paul O'Neill, is "an unusual combination of scholar and practitioner" (2001: xiii). As coauthor Ruby Beale explained, Cox was "one of the few research types who could understand the scholar-researcher perspective and the practitioner-consultant arena. That was his true gift."

Cox combined diversity scholarship with diversity consulting to the most senior-level corporate executives. He was adept at spanning multiple communities, and he drew on this boundaryspanning skill to develop a portfolio of consulting activities that ranged from cultural audits, program development, workshops and trainings to advising and coaching CEOs and corporate diversity steering committees. He worked with U.S. govern- ment agencies (such as the Dept. of Justice and Fannie Mae) and large national and international corporations (such as Exxon, Alcoa, and Eli Lily). Cox also worked with international audiences with different histories and diversity challenges. For example, he lectured and taught workshops in Australia to address the diversity challenges posed by historic discrimination against ethnic (native) communities. And, Cox served as a consultont to a university administrator in South Africa who was trying to break down the negative influences of apartheid. The relevance of Cox's work to both practice and theory, across boundaries of nationality and history, testifies to the breadth of his contributions.

The relevance of Cox's work to both practice and theory, across boundaries of nationality and history, testifies to the breadth of his contributions.

Cox focused his consulting work on a single goal: teaching organizations and their members how to develop their ability to respond to diversity challenges. For him, consulting went beyond offering analysis and advice. In each of his consulting engagements, he taught people how to become competent, thoughtful leaders of diversity-based organizational change. As he helped managers who were struggling to put a theoretical understanding of multiculturalism into practice, Cox worked to translate research insights into teaching and learning tools. As he drew on his research to understand the specific diversity-related organizational and individual challenges that organization members were confronting, he also used his experience as a teacher to create models, exercises, and programs that educators could use in their diversity education efforts. Cox's process of applying theory to managerial practice and real-time diversity dilemmas, and then using his insights about diversity challenges to create learning tools and new questions, established the foundation for the Managing Diversity Competency model (Cox \& Beale, 1997). This model is the centerpiece of Cox's most comprehensive teaching resource, Developing Competency to Manage Diversity (1997), which he wrote with Beale.

Cox and Beale's Developing Competency to Manage Diversity (1997), a collection of teaching cases, readings, and learning activities, was one of the first diversity teaching resources to address challenges at both the individual and organizational levels. It was quickly adopted by academic 
colleagues who were teaching diversity at the undergraduate and graduate levels and by consultants who were involved in diversity training. Cox and Beale resisted the pressure to offer a list of skills for managing diversity; instead, they focused on teaching individuals how to learn about diversity and about responding effectively to diversity challenges. Their fromeworks helped readers understand and analyze how the dynamics of diversity issues affect the individual's specific organization. Their cases and exercises helped students learn how to change their own behavior and also enabled managers to become more effective leaders of diversity change. Cox and Beale's approach-"teaching people how to fish"—did not promise an easy path to quick results. Instead, they encouraged readers to seek lasting organizational and personal growth by pursuing a more challenging, yet still practical and realistic, form of diversity education and training.

\section{Social Action-Change Agent in the University and the Academy}

Cox not only advised change agents with his research and consulting, he also acted as a change agent in his own university and in the Academy of Management. He used his research to challenge the field by openly calling into question the reticence of the academy in publishing research on cultural diversity, especially racioethnicity.

\section{Challenging the Academy}

We see the social action aspect of Cox's research agenda in full force in his (1990) paper "Problems With Research by Organizational Scholars on Issues of Race and Ethnicity." This paper won a McGregor Award (presented by the NTL Institute and Sage Publications) for best articles of 1990 1999 in the Journal of Applied Behavioral Science. In his editorial comments introducing the special issue, Clayton Alderfer (2004) noted:

Taylor Cox reports on a research project that he conducted to determine why the management school literature of the 1980s had decreased the attention given to black-white relations. Although the stresses faced by black researchers were more severe than those encountered by whites, the overall picture was one in which race relations investigators faced special hurdles not customarily found for other topics covered in management school journals. The subject matter was demeaned by advisers, journal editors, and re- viewers. Authors faced particularly irrational scrutiny of their methodology when submitting papers for review (Alderfer, 2004: 121122).

Also in 1990, Cox and Nkomo published "Invisible Men and Women: A Status Report on Race as a Variable in Organizational Behavior." In this study, they used data about the very publications representing the gold standard in management research to make their case that the academy was ignoring racioethnicity as a legitimate management topic. By challenging educators and researchers with these empirical studies, Cox was a "practitioner" and catalyst for change in the academy.

\section{Creating Systems to Expand Diversity Within the Academy}

Cox went beyond challenging the academy to be more inclusive regarding accepting and valuing research on cultural diversity. He also acted to create systems and institutions that would bring diversity to business academics. Some of this work was directed at the academy, some at students, and some through role modeling and gentle advocacy at the University of Michigan. Cox was consistent and generous in his support of other researchers who were studying diversity, offering them advice, recommendations, sponsorship and research opportunities. He also got involved through leadership roles in the Academy of Management, including symposia development and participation, reviewing, and contributions to the Women \& Management division (forerunner to the Gender and Diversity in Organizations division).

Perhaps the most significant educational system that Cox helped to establish and to maintain was the Minority Summer Institute (MSI), the precursor to The PhD Project. Sponsored by the Graduate Management Admissions Council, this program offered African-American, Native-American, and Hispanic-American college juniors from across the country an opportunity to experience predoctoral courses at the University of Michigan. Cox described the influence of the Minority Summer Institute and his diversity education work this way:

If you ask me what are some of the things that are most satisfying to me about my work history with diversity, one of them would certainly be the Summer Institute, encouraging people to pursue doctoral studies, and related to that, encouraging students to think about work on diversity as a possible avenue of 
focus. That was certainly a piece of my background that was very satisfying.

Cox demonstrated a multicultural (i.e., nontraditional, nonpatriarchal, and inclusive), relational orientation in his support of other colleagues and scholars. Similarly, he enacted his multicultural model by mentoring protégés from diverse racioethnic backgrounds. As an iconoclast pushing boundaries, Cox demonstrated that collaborations could be a powerful form of social action that had the potential to change the lives of his peers, protégés and the academy as a whole.

\section{The Power of Collaboration}

A final aspect of Cox's impressive career is the generosity with which he collaborated with others, not only peer colleagues, but also junior colleagues and students. He provided research and coauthoring opportunities, taught what he knew, kept open to learning from others, offered mentoring and career support, and exemplified a strong role model for others who wanted to address transgressive, different, sensitive, value-laden topics.

Because we had the opportunity to collaborate with Cox, we knew that any discussion of his impact on the field would be incomplete without some attention to the partnerships that he built over the course of his career. Cox described "the opportunity to work with very gifted people" as instrumental in contributing to his ambitious agenda regarding diversity research and education. In preparation for this retrospective, we interviewed several of Cox's collaborators to get their sentiments on the impact of their work with him.

One collaborative relationship previously mentioned was Cox's partnership with Stella Nkomo. She indicated that in addition to publishing on impressive stream of coauthored articles, working with Cox helped her stay motivated and focused in spite of discouraging responses from top-tier journals where they were submitting their studies on race. Nkomo talked about being impressed and heartened by Cox's persistence and support:

We had real data, our sample size was good, we had looked at all the variations and we still couldn't get this study published. A well known journal had turned it down ... So Taylor said, Okay-let's lick our wounds and get it out again. Taylor had persistence. He was clear that we needed to find another journal that was more open. We sent it out again and it was accepted ... We decided we were going to get this work done even if we were going to be disappointed. I really appreciated how we supported one another-we would get back the reviews and talk with one another. It gave us fortitude.

A common value held in the academy is that discipline-based scholarship is superior to applied research. In their work together, Ruby Beale and Cox demonstrated that this belief was not true. Scholarship and applied research both matter; practice could and should inform research. As a consultant who was transitioning back into academia, Beale recognized how her work with Cox refuted some messages that she saw operating:

Some of us are made to think that being in the academy means that being applied is not that important, certainly not from an intellectual possibility. But in fact, practice can help shape the questions we ask for research, not just the other way around.

George Dreher, with whom Cox published an influential article on the impact of race and gender on mentoring relationships (Dreher \& Cox, 1996), shared the following insights:

I learned a lot about the research process. In particular, Taylor helped me understand the need to form research teams when considering diversity-oriented issues-teams that are themselves diverse. The notion that $\alpha$ straight, secular, white, middle-aged man who grew up in the Bay area in the 1960s needed more than the research skills taught in a Ph.D. program to be able to consider and to understand the complex questions being addressed by diversity scholars was the topic of one of my early discussions with Taylor. Taylor was always willing to help me better understand the dynamics of organizational life (and the messages coming from our research data) from the African-American perspective. And I always felt that he found me to be equally valuable as a source of cultural information and perspective.

Cox did not limit his research to fellow faculty members; he also closely mentored a number of doctoral students during his time at University of Michigan (Cox \& Blake, 1991; Cox \& Finley, 1995, 1997; Cox \& Harquail, 1991, 1993). As Cox's former doctoral student protégés, we offer key insights gained from our collaboration with him.

Stacy Blake-Beard recalls Cox's generosity and 
integrity in her collaboration with him on the "Managing Cultural Differences" manuscript:

I was a relatively new doctoral student when I approached Taylor about working with him on his research. Right away, I was drawn into Taylor's passion and dedication to his work. As we worked on the article, I was appreciative of Taylor's generosity in offering me second author on this paper. I had a sense that this paper was going to be important, that we were reaching for arguments and drawing conclusions that would be helpful to those interested in the business case for diversity, practitioners and researchers alike. Taylor's collaboration with me and several other doctoral students also served another purpose. Taylor was seeding the way, preparing a new generation of scholars to continue the research on diversity.

Joycelyn Finley-Hervey spoke about Cox's support of her career decisions at a time when that support was critically needed:

On a personal and professional level, he made sure that I understood that my choice to teach at a Historically Black College and University (HBCU) was not only one that I should pursue but it was also acceptable, appropriate, and commendable. Through his own experience, he had found this path to be a valuable one. He had experienced both HBCU and majority institution environments and networks. So his support was instrumental in my pursuing and securing a position within a HBCU. Other faculty members were telling me that I would waste my degree at a teaching institution and that I should only work at a top-tier research university. Taylor was a role model because his career path had not been traditional. His experience validated those of us who were outsiders within.

Celia Virginia Harquail acknowledged learning about building effective partnerships from Cox:

I learned so much about collaboration from Taylor. I appreciated his confidence in my abilities and I appreciated the ways he trusted me to do significant parts of our work. Taylor would also listen to my ideas and work with me as a collaborator. He let me challenge him, ask questions, and suggest new directions, as a collaborator and not just as a doctoral student. And even though he was teaching me how to conduct research, he was also willing to learn from me and to learn along with me. He treated me like a person who knew something and whose insights mattered.

She also noted that as part of working outside of more traditional areas of scholarship, "Taylor showed me how much harder, how much more correct and how much more accurate your work had to be if it was going to confront the status quo. It had to be perfect to withstand the withering critique." Each of us remembers how much involvement and control Cox gave us in the research process. What stood out was his willingness to incorporate our perspective and learning. We realized that our relationships with Cox were untraditional and did not reflect other, more common configurations of faculty-student interactions.

Although our collaborative relationships with Cox were each unique, three themes were common to every collaborator's recollections. Each collaborator believed that one of Cox's greatest contributions to education and training was opening the door to make diversity a legitimate field of study and practice. Each collaborator articulated some measure of sadness at seeing him leave the academy upon retirement; at the same time, each also appreciated Cox's dedication to his faith and his calling to do work outside of the academy. Finally, all collaborators mentioned how grateful they were that Cox had been part of their personal and professional journey.

\section{Future Opportunities for Diversity Education, Training, and Research}

The theme for this issue, Diversity Education and Training: What We Know and What We Need to Know, provides ample guidance for closing reflections from this review. Interestingly, Cox's concluding thoughts addressed both questions embedded in the theme. One thing we know is that diversity education and diversity research inform one another. Cox said the following of the interconnection between education and research:

If you go into an organization and you examine performance appraisal ratings and their relationship to identity factors like gender or race or national origin, that may suggest to you certain patterns or certain relationships that then start a research project to investigate a theory about why I am seeing what I am seeing. 
We also know that there are challenges facing those who are implementing education efforts and conceptualizing research; both suffer from misaligned objectives and an underestimation of the complexity of the subject. Finally, we know that despite these problems, it is imperative that we continue offering diversity education and training. While Cox acknowledged that some training is not effective, he testified to the potential of diversity training:

Anyone who has been extensively involved in educational sessions on this topic has seen, firsthand, the transformation of people, their thinking and their behavior. There's no doubt in my mind that this training can have on impact and we need to keep doing it. Training and other forms of education are certainly major levers for organizational transformation.

There is still much that we need to know about diversity and organizations. One question that merits additional attention is how we can develop better strategies for assessing the effectiveness of diversity efforts, so that organizations can see the links between education, multicultural competence, and organizational effectiveness. Cox suggests that we go beyond offering improved preand postintervention measures and recommends that we consider testing people's ability to solve diversity-related problems, or measuring changes in relevant aspects of diversity-related behavior across an organization. He believes that rigorous strategies for assessing diversity efforts will need, at the very least, to (l) incorporate the influence of an organization's context; (2) consider the scope of the effort (e.g., time allocated, percent of members participating, etc.); and (3) acknowledge the level of motivation, enthusiasm, and initial skills of the porticipants.

With so many organizations paying attention to the challenges and opportunities of workforce diversity, we can ask a second question: "What is next?" In "Taking Diversity to the Next Level," Cox (2002) specifically addresses this question. For organizations that have begun their diversity efforts, he offers five elements to gain traction with their education and training initiatives. These five elements include: $(\alpha)$ securing the commitment of top leaders and their willingness to ask tough questions and provide ongoing communication; (b) conducting internal research that provides support for diagnosing the corporate culture and that builds the business case for investing in diversity; (c) creating and implementing comprehensive multiyear education plans that integrate diversity with other topics; (d) aligning management systems with diversity efforts so that the systems that support people in the organization are also supporting diversity education and training; and, (e) establishing a system of accountability that is based on how progress on diversity goals is being met.

\section{Conclusion and Call to Action}

Through our examination of Taylor Cox's journey, we step away with insights and lessons that are needed now more than ever. As far as diversity education, training, and research have come, we still face a number of essential questions and concerns. There is still skepticism about the value of diversity education and training. Why are we doing this? We still see examples of organizations implementing diversity training in superficial rather than substantive ways. How are we doing this? We still feel the tension of whether diversity should be positioned as a business opportunity or a cause for social action. What should our impetus be? We still have dilemmas about how diversity is defined. What are we looking at? In light of these unresolved issues, Cox offers the following topics as a call to action for teachers, trainers, and researchers: (1) investigate the effectiveness of diversity training in relation to team building, communication, and managing change; (2) probe the relationship between diversity education and affirmative action; (3) expand diversity training to incorporate issues specific to immigration; (4) explore the impact of globalization on diversity training; (5) evaluate diversity competence education; (6) study diversity in thought patterns; and (7) analyze the relationships between diversity and work function.

Through our examination of his journey as a researcher, scholar-practitioner and powerful agent of change, we step away with one of Cox's most important lessons-diversity is not a problem to be fixed, diversity is an opportunity to be leveraged.

We are at a pivotal moment in organizations, where questions about the relevance and impact of diversity training and education are at the fore (Kalev, Dobbin, \& Kelly, 2006; Page, 2007). Cox's work provides us a foundation as we face challenging times and important decisions regarding the future and fate of diversity education and train- 
ing. Through our examination of his journey as a researcher, scholar-practitioner and powerful agent of change, we step away with one of Cox's most important lessons-diversity is not a problem to be fixed, diversity is on opportunity to be leveraged. Cox's wisdom and perspective provide us with a critical beacon as we continue on this journey to a different place.

\section{REFERENCES}

Alderfer, C. P. 2004. Editor's introduction. Journal of Applied Behavioral Science, 40(2): 121-123.

Cox, T. H. 1983. Blacks and higher education: Where do we stand and what difference does it make anyway? Negro Education Review, 24(1): 4-11.

Cox, T., Jr. 1990. Problems with research by organizational scholars on issues of race and ethnicity. Journal of Applied Behavioral Science, 26(1): 5-24.

Cox, T., Jr. 1991. The multicultural organization. Academy of Management Executive, 5(2): 34-47.

Cox, T., Jr. 1993. Cultural diversity in organizations: Theory, research \& practice. San Francisco, CA: Berrett-Koehler.

Cox, T., Jr. 2001. Creating the multicultural organization: A strategy for capturing the power of diversity. San Francisco, CA: Jossey-Bass.

Cox, T. 2002. Taking diversity to the next level. Executive Excellence, 19(4): 19.

Cox, T., Jr., \& Beale, R. L. 1997. Developing competency to manage diversity: Readings, cases \& activities. San Francisco, CA: Berrett-Koehler.

Cox, T. H., \& Blake, S. 1991. Managing cultural diversity: Implications for organizational effectiveness. Academy of Management Executive, 5(3): 45-56.

Cox, T. H., \& Finley-Nickelson, J. 1991. Models of acculturation for intraorganizational diversity. Canadian Journal of Administrative Science, 8(2): 90-100.

Cox, T. H., \& Finley, J. 1995. An analysis of work specialization and organization level as dimensions of workforce diversity. In M. Chemers, S. Oskamp, \& M. Costanzo (Eds.), Diversity in organizations: New perspectives for a changing workplace: 62-88. Thousand Oaks, CA: Sage.

Cox, T., Jr., \& Finley, J. 1997. The process of acculturation in diverse organizations. In T. Cox, Jr., \& R. L. Beale (Eds.),
Developing competency to manage diversity: Readings, cases \& activities. San Francisco, CA: Berrett-Koehler.

Cox, T. H., \& Harquail, C. V. 1991. Career paths and career success in early career stages of male and female MBAs. Journal of Vocational Behavior, 39: 54-75.

Cox, T. H., \& Harquail, C. V. 1993. Organizational culture and acculturation. In T. H. Cox, Cultural diversity in organizations: 161-177. San Francisco: Berrett-Koehler.

Cox, T. H., Lobel, S., \& McLeod, P. 1991. Effects of ethnic group cultural differences on cooperative vs. competitive approaches in a group task. Academy of Management Journal, 34(4): 827-847.

Cox, T., Jr., \& Nkomo, S. M. 1986. Differential performance appraisal criteria: A field study of black and white managers. Group \& Organization Studies, 11(1-2): 101-119.

Cox, T. H., \& Nkomo, S. M. 1990. Invisible men and women: A status report on race as a variable in organizational behavior research. Journal of Organizational Behavior, 11: 419-431.

Cox, T. H., \& Nkomo, S. M. 1991. A race and gender-group analysis of the early career experience of MBAs. Work \& Occupations, 18(4): 431-446.

Dreher, G. F., \& Cox, T. H. 1996. Race, gender and opportunity: A study of compensation attainment and the establishment of mentoring relationships. Journal of Applied Psychology, 81(3): 297-308.

Kalev, A., Dobbin, F., \& Kelly, E. 2006. Best practices or best guesses? Assessing the efficacy of corporate affirmative action and diversity policies. American Sociological Review, 71(4): 589-617.

McLeod, P., Lobel, S., \& Cox, T. H. 1996. Ethnic diversity and creativity in small groups. Small Group Research, 27(2): 248-264.

Nkomo, S. M., \& Cox, T., Jr. 1989. Gender differences in the upward mobility of black managers: Double whammy or double advantage? Sex Roles, 21: 825-839.

Nkomo, S. M., \& Cox, T., Jr. 1990. Factors affecting the upward mobility of black managers in private sector organizations. Review of Black Political Economy, 18(3): 39-57.

O'Neill, P. H. 2001. Foreward. In T. Cox Jr., Creating the multicultural organization: A strategy for capturing the power of diversity. San Francisco, CA: Jossey-Bass.

Page, S. E. 2007. Making the difference: Applying a logic of diversity. Academy of Management Perspectives, 21(4): $6-20$. 


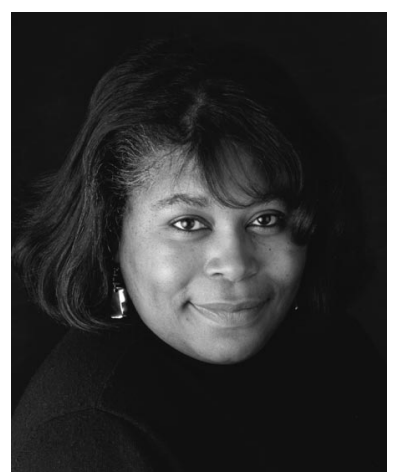

Stacy Blake-Beard (PhD, University of Michigan) is associate professor of management at Simmons College and research faculty with the Center for Gender in Organizations. She serves on the Executive Board for the Gender and Diversity in Organizations Division. Her research interests include the impact of diversity on mentoring relationships.

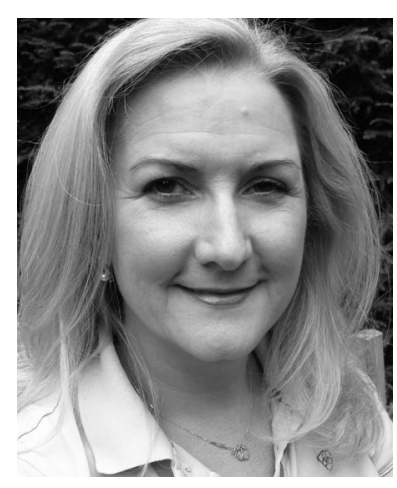

Celia Virginia (CV) Harquail ( $\mathrm{PhD}$, University of Michigan) is a consultant, independent scholar, and writer-moderator of the blog www. AuthenticOrganizations. com. Her research has been published in ASQ, AMJ and JMI, and she serves on the editorial board of the Academy of Management Review. Her research and consulting address issues of organizational identity, image, branding, and authenticity.

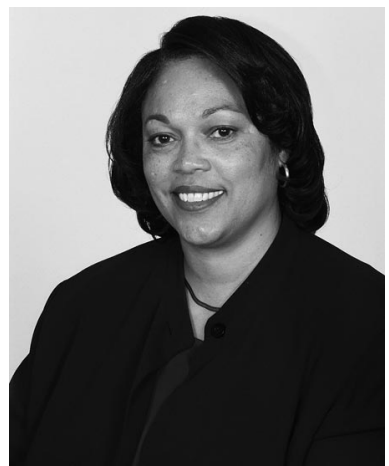

Joycelyn Finley-Hervey ( $\mathrm{PhD}$, University of Michigan) is a professor of management in the School of Business \& Industry at Florida A\&M University. Her research examines cultural diversity, communication, and intergroup relations. She serves as the Academy of Management Gender and Diversity in Organizations Treasurer and Past Cochair of the Academy's Mentoring Committee. 